\title{
A case of early onset Parkinson's disease after major stress
}

\author{
This article was published in the following Dove Press journal: \\ Neuropsychiatric Disease and Treatment \\ I August 2013 \\ Number of times this article has been viewed
}

\section{Ke Zou' \\ Wanjun Guo \\ Gongshun Tang ${ }^{3}$ \\ Bo Zheng ${ }^{4}$ \\ Zhong Zheng'}

'Neurobiological Laboratory, ${ }^{2}$ Mental Health Center, ${ }^{3}$ Department of Nuclear Medicine, West China Hospital of Sichuan University, Chengdu, People's Republic of China; ${ }^{4}$ Huaxi Clinical College, Sichuan University, Chengdu, People's Republic of China
Correspondence: Zhong Zheng Neurobiological Laboratory, West China Hospital of Sichuan University, 28 South Dianxin Road, Chengdu, Sichuan 61004I, People's Republic of China

Tel +86 2885422783

Fax +862885422733

Email zhengzhong19638t@gmail.com
Abstract: A 38-year-old woman experienced sudden onset of rest tremor in the left forearm 1 week after learning that her deeply loved husband was involved in an affair. The patient was in good health and had no neurological disease or prior trauma. The surface electromyography results were consistent with features of the typical rest tremor, and the increased glucose metabolism in the putamen, seen on positron emission tomography scan, was consistent with the early stages of Parkinson's disease (PD). Furthermore, her trembling symptoms were relieved significantly after antiparkinsonian medications. For this patient, stress played an important role in the development of PD. The mechanism may have been the direct effects of numerous neurotransmitters or dopamine depletion after its massive release during severe stress. This case suggests that severe stress can worsen the neurological symptoms and prompted early onset of PD. It is the first case of PD occurring so early in life after exposure to major stress, and arouses our attention to the effects of stress on the nervous system.

Keywords: Parkinson's disease, early onset, stress, positron emission computed tomography, surface electromyography

\section{Case report}

It is well known that stress can impact the hippocampus in a number of deleterious ways, including disruption of neurogenesis, atrophy of dendritic processes, and overt neurotoxicity, and can lead to posttraumatic stress disorder. ${ }^{1}$ While in clinic, some neurological disorders are diagnosed after exposure to stress. Here is a case of early onset Parkinson's disease (PD) after major stress.

On June 7, 2009, a 38-year-old woman experienced extreme depression after learning that her deeply loved husband was involved in an affair. Simultaneously, she suffered from insomnia, anxiety, and anorexia. One week later, there was a sudden onset of rest tremor in her left forearm. She underwent head magnetic resonance imaging examination and blood tests for tumor markers; no abnormalities were found. This patient was admitted to our Department of Psychiatry on June 16, 2009. Besides rest tremor and hypokinesia, she had cogwheel rigidity in the left forearm and her 17-item Hamilton Depression Rating Scale (HDRS) score was 38. No pathological reflex was elicited. Routine examinations were normal, and there were no abnormalities in ceruloplasmin level or thyroid hormone tests. Sertraline $50 \mathrm{mg} /$ day was started, the dosage was gradually increased to $100 \mathrm{mg} /$ day, and lorazepam $1 \mathrm{mg}$ three times a day was initiated at the same time. Her depressed symptoms relieved and her HDRS score decreased to 28 , but there was no obvious improvement in 
trembling. On June 21, surface electromyography (EMG) on her resting left forearm showed "alternating activities of extensor and flexor at a constant frequency of $6 \mathrm{~Hz}$." She was then given Madopar $^{\circledR}$ (Levodopa/Benserazide $250 \mathrm{mg}$ [200 mg of Levodopa and $50 \mathrm{mg}$ of Benserazide], Roche, Basel, Switzerland) $125 \mathrm{mg}$ three times a day additionally, and on June 26, positron emission tomography (PET) with ${ }^{18} \mathrm{~F}$-fluorodeoxyglucose showed "increased glucose metabolism in the bilateral putamen, more obviously in the right side" (Figure 1). Immediately, the patient was transferred to the Department of Neurology on July 10. She was given Madopar $62.5 \mathrm{mg}$ three times a day and amantadine $100 \mathrm{mg}$ twice daily. Her tremor symptoms relieved significantly, and her HDRS score further decreased to 21. She was discharged on July 14, 2009 with Madopar $62.5 \mathrm{mg}$ twice daily and amantadine $100 \mathrm{mg}$ twice daily. This patient is still being followed in outpatient clinics once a month. She is being treated with a dose of carbidopa/levodopa 25-100 mg (25 mg carbidopa and $100 \mathrm{mg}$ levodopa) twice daily. She has stable emotions, and her movements are slightly slow sometimes. She experiences occasional resting tremor of the left forearm, which is a little more evident when excited.

The major evidence for diagnosing this case as PD are as follows. First, we have verified that she had no severe or acute medical conditions, both past and present. Second, the EMG results were consistent with features of the typical resting tremor, ie, alternating activity of antagonistic muscles with a frequency of 3-7 Hz. ${ }^{2}$ Third, at the early stage of PD, $\mathrm{D}_{2}$

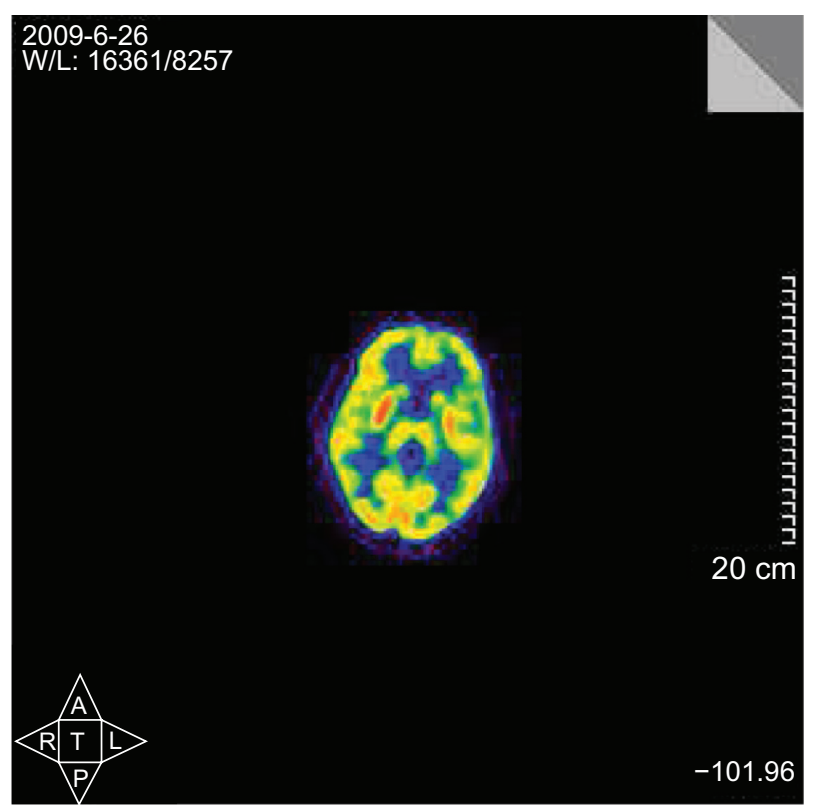

Figure I Increased glucose metabolism of the bilateral putamen with positron emission tomography scan, more obvious on the right side. receptors in the striatum were upregulated, ${ }^{3,4}$ and $\mathrm{D}_{2}$-receptor binding in both the caudate nucleus and putamen had a positive correlation with the metabolic rate for glucose in early PD. ${ }^{5}$ Eidelberg et al suggested that in early stages of PD, increased glucose metabolism in the putamen was related to the complex feedback mechanism induced by striatal dopamine dysfunction. ${ }^{6}$ Thus, the increased glucose metabolism in the putamen, seen on PET scan, is consistent with the early stages of the disease. Lastly, antiparkinsonian medications were effective.

This is a very interesting case, because PD is rarely seen at such an early age. We know that incidence rises after the age of 55 years and onset rarely occurs before age 40 years. ${ }^{7}$ It has been suggested that age at onset of PD is later in women than in men. ${ }^{8}$ For this patient, stress played an important role in the development of $\mathrm{PD}$, and it has been proposed that emotional stress could transiently increase motor symptoms. ${ }^{9}$ Snyder and colleagues also suggested that appearance of the clinical PD symptoms during a stressful period may reflect damage to the nigrostriatal system that had been masked during the preclinical stage. ${ }^{10}$ In the striatum, stress increases the extracellular availability of glucocorticoids, dopamine, and glutamate. These all have the capacity to harm neurons separately, and perhaps can even act in a synergistic manner to cause or exacerbate neuronal damage. ${ }^{11}$ Furthermore, it has been found in rats that during stress exposure, glutamate could promote dopamine release through acting on $\mathrm{N}$-methylD-aspartate receptors in the substantia nigra. ${ }^{12}$ So, stress might indeed be a key factor in the loss of dopamine neurons that underlies PD. ${ }^{11}$ Therefore, major stress can worsen neurological symptoms and prompt early onset of PD, despite the greatest risk factor for PD being aging.

To our knowledge, this is the first case of PD occurring so early in life after exposure to major stress. It is enough to arouse our attention to the effects of stress on the nervous system. Further studies are warranted to elucidate more fully the mechanisms between PD and stress.

\section{Disclosure}

The authors report no conflicts of interest in this work.

\section{References}

1. Sapolsky RM. Atrophy of the hippocampus in posttraumatic stress disorder: how and when? Hippocampus. 2001;11(2):90-91.

2. Hallett M. Electrophysiologic evaluation of tremor and central disorder of movement. In: Aminoff MJ, editor. Electrodiagnosis in Clinical Neurology. 2nd ed. New York: Churchill Livingstone; 1986:385-401.

3. Rinne JO, Laihinen A, Rinne UK, Någren K, Bergman J, Ruotsalainen U. $\mathrm{D}_{2}$ receptor changes during the progression of early Parkinson's disease. Mov Disord. 1993;8(2):134-138. 
4. Rinne JO, Laihinen A, Ruottinen $\mathrm{H}$, et al. Increased density of dopamine $\mathrm{D}_{2}$ receptors in the putamen, but not in the caudate nucleus in early Parkinson's disease: a PET study with [11C]raclopride. J Neurol Sci. 1995;132(2):156-161.

5. Nakagawa M, Kuwabara Y, Taniwaki T, et al. PET evaluation of the relationship between $\mathrm{D} 2$ receptor binding and glucose metabolism in patients with parkinsonism. Ann Nucl Med. 2005;19(4):267-275.

6. Eidelberg D, Moeller JR, Ishikawa T, et al. Early differential diagnosis of Parkinson's disease with 18F-fluorodeoxyglucose and positron emission tomography. Neurology. 1995;45(11):1995-2004.

7. Brownell AL, Canales K, Chen YI, et al. Mapping of brain function after MPTP-induced neurotoxicity in a primate Parkinson's disease model. Neuroimage. 2003;20(2):1064-1075.

8. Haaxma CA, Bloem BR, Borm GF, et al. Gender differences in Parkinson's disease. J Neurol Neurosurg Psychiatry. 2007;78(8): 819-824.
9. Macht M, Brandstetter S, Ellgring H. Stress affects hedonic responses but not reaching-grasping in Parkinson's disease. Behav Brain Res. 2007;177(1):171-174.

10. Snyder AM, Stricker EM, Zigmond MJ. Stress-induced neurological impairments in an animal model of parkinsonism. Ann Neurol. 1985;18(5):544-551.

11. Smith AD, Castro SL, Zigmond MJ. Stress-induced Parkinson's disease: a working hypothesis. Physiol Behav. 2002;77(4-5):527-531.

12. Keefe KA, Sved AF, Zigmond MJ, Abercrombie ED. Stress-induced dopamine release in the neostriatum: evaluation of the role of action potentials in nigrostriatal dopamine neurons or local initiation by endogenous excitatory amino acids. J Neurochem. 1993;61(5):1943-1952.

\section{Publish your work in this journal}

Neuropsychiatric Disease and Treatment is an international, peerreviewed journal of clinical therapeutics and pharmacology focusing on concise rapid reporting of clinical or pre-clinical studies on a range of neuropsychiatric and neurological disorders. This journal is indexed on PubMed Central, the 'PsycINFO' database and CAS.
The manuscript management system is completely online and includes a very quick and fair peer-review system, which is all easy to use. Visit http://www.dovepress.com/testimonials.php to read real quotes from published authors.

Submit your manuscript here: http://www.dovepress.com/neuropsychiatric-disease-and-treatment-journal 